\title{
Adaptive Capabilities of Laboratory Rats Living in Conditions of Atmospheric Emissions of the Industrial Complex \\ ${ }^{1}$ Nina N. Zabolotskaya, ${ }^{2}$ Ramil T. Nasibullin \\ ${ }_{1,2}$ Kazan Federal University \\ Email: nasibullin.ramil@mail.ru
}

Received: 02 ${ }^{\text {nd }}$ November 2018, Accepted: $28^{\text {th }}$ November 2018, Published: $31^{\text {st }}$ December 2018

\begin{abstract}
Industrial enterprises, being sources of environmental pollution, directly and indirectly affect human health. In this regard, the problem of the effects of atmospheric emissions on the respiratory system and the immune system is extremely important. The task was to study the adaptive capacity of the organism of laboratory rats, which are an adequate model of the human body in conditions of air pollution by emissions from a metallurgical industrial complex. The complex effect of atmospheric emissions from a metallurgical enterprise on growing laboratory rats was studied in a full-scale experiment, when experimental animals were placed in specially equipped chambers installed at different distances from the industrial complex: at a distance of $1000 \mathrm{~m}$ (the first group of animals -25 individuals) and 20000 $\mathrm{m}$ (the second group of animals - 25 individuals). In addition to these animals, three more groups of laboratory rats (25 animals in each group) placed in chambers with a specially prescribed mode, into which purified air was continuously fed with the addition of phenol, as one of the components of the atmospheric emissions of a metallurgical enterprise, participated in the experiment. $3.0 \mathrm{mg} / \mathrm{m}^{3}, 0.1 \mathrm{mg} / \mathrm{m}^{3}, 0.001 \mathrm{mg} / \mathrm{m}^{3}$. Assessment of the adaptive capabilities of animals was carried out for four months, that is, from the neonatal period to the period of puberty according to a number of parameters, after which histological studies of the respiratory organs and spleen structures were performed. Histological studies revealed that in the organs of rats of the first group, changes in the type of irritation prevailed with areas of atrophy of the mucous membrane of the bronchial mucosa, as well as hyperplasia of lymphoid structures of the spleen with an increase in the growth centers of lymphoid follicles, pathological changes in the investigated organs of animals of the second group defined as a slight hyperplasia tracheal gland hyperplasia lymphoid follicles of the spleen and the absence of any changes in bronchial structures throughout the observation period. In a full-scale experiment, the adaptive abilities of animals are significantly reduced in individuals of the first group, which is confirmed by histological studies: the presence of pronounced irreversible changes in the organs of immunogenesis, in the mucous membranes of the trachea and bronchi.

Harmful substances of atmospheric emissions of industrial enterprises, both comprehensively and individually, as in the experiment presented - phenol, can disrupt the adaptation capabilities of the organism.
\end{abstract}

\section{Keywords}

Adaptive Capabilities; Laboratory Rats; Atmospheric Emissions; Industrial Complex; Phenol; Respiratory System; Organs of Immunogenesis.

\section{Introduction}

The life of a modern person in a city is fraught with many risks, which is especially characteristic of cities with a developed industrial infrastructure. Despite ongoing environmental protection measures, industrial enterprises continue to pollute the atmosphere, hydrosphere and soil, which cannot but affect the health of people and their health and safety [1].

Metallurgical production today is guided by the law of the Russian Federation "On Environmental Protection", which is the main legislative document in the field of environmental safety of metallurgy. The activities of enterprises are regulated by the Sanitary Rules and Health Ministry Standards [2]. This document refers to the creation of sanitary protection zones (SPZ) near enterprises. The boundaries of the sanitary protection zone (SPZ) indicate the value of the most acceptable sanitary distance between the residential sector and enterprises, which guarantees a positive state of air in the atmosphere even in case of release of harmful untreated substances. But the most important document on the environmental activities of metallurgical enterprises in the Russian Federation is the environmental standard GOST R ISO 14001, developed on the basis of the international system of standards ISO 14000, which, in turn, are guided by the countries of the European Union, Japan, the United States and others. The peculiarity of this system is that it focuses not on technology, quantitative or qualitative indicators (amount of emissions, concentration of substances, etc.), but on the environmental management system (EMS) (or the EMS - environmental management system - edited GOST R ISO 14001). It should be noted that environmental management is the highest priority of industrial activity in the twentyfirst century. The largest contribution to air pollution (in terms of emissions) was made by electric power industry enterprises (29.1\% of total industrial emissions), non-ferrous (22\%) and ferrous (14.6\%) metallurgy (Fig. 1) [3]. Interesting work, which presents data on the impact of atmospheric emissions of metallurgical enterprises, which are one of the main sources of air pollution, on public health. Basically, in the literature provides information on the 
combined effects of environmental factors on the human body [4]. Studies have established that the main emissions from metallurgical plants are dust, carbon monoxide, hydrogen sulphide, a number of hydrocarbons, including phenol, as well as other harmful substances. [5,6]. According to sanitary and hygienic characteristics, phenol is a substance of the second class of danger, it has a large summation effect, causes damage to the respiratory tract, malignant formations, cardiovascular diseases, disruption of the vegetative system [7]. The main sources of phenol release into the environment are metallurgical and coke-chemical plants. The average daily MPC of a pollutant in atmospheric air is 3 $\mu \mathrm{g} / \mathrm{m}^{3}$ [8]. The content of phenols in the air of large industrial cities often exceeds the MAC [9]. All substances that pollute the atmospheric air have a negative effect on human health, causing pathological changes, primarily in the respiratory organs, which are the main way of their penetration into the human body [10]. Moreover, about $50 \%$ of particles of emissions with a radius of 0.01-0.1 $\mu \mathrm{g}$, penetrating into the lungs and deposited in them. The state of the atmosphere affects the incidence rates even in different areas of industrial cities [11]. Predisposition to bronchial asthma, bronchitis, conjunctivitis, pharyngitis, tonsillitis, chronic otitis media is 40-60\% higher in areas with high levels of air pollution. Statistical analysis allowed to establish the relationship between the level of air pollution and diseases such as lesions of the upper respiratory tract, bronchitis, asthma, pneumonia, pulmonary emphysema [12].

The task was to study the adaptive capacity of laboratory rats, which are an adequate model of the human body in conditions of air pollution by emissions of the metallurgical industrial complex in order to find out the reasons for the increased bronchovascular morbidity in the region.

\section{Methods}

The complex effect of atmospheric emissions of a metallurgical enterprise on growing laboratory rats was studied by us in a field experiment, when experimental animals were housed in specially equipped chambers installed at different distances from the industrial complex: at a distance of $1000 \mathrm{~m}$ (the first group of animals - 25 individuals) and $20000 \mathrm{~m}$ (the second group - 25 individuals). According to the sanitary classification of enterprises, the length of the sanitary protection zone (SPZ) for first-class facilities is $1000 \mathrm{~m}$. The boundaries of the sanitary protection zone (SPZ) indicate the most acceptable sanitary distance between the residential sector and enterprises. Sanitary protection zones guarantee a positive state of air in the atmosphere, even in case of release of harmful untreated substances. In addition to the two groups of animals listed above, in the experiment three more groups of laboratory rats ( 25 animals in each group) were placed in chambers with a specially prescribed mode, into which purified air was continuously supplied with the addition of phenol as one of the components of atmospheric emissions from a metallurgical enterprise. concentrations of $3.0 \mathrm{mg} / \mathrm{m}^{3}, 0.1 \mathrm{mg} / \mathrm{m}^{3}, 0.001 \mathrm{mg} / \mathrm{m}^{3}$. In the experiment, for the purity of the results, new-born male rats were selected, which made it possible to evaluate the reactions of the growing organism. It is known that a rat reaches puberty at 4 months. Evaluation of the adaptive capabilities of animals was carried out for four months, that is, from the neonatal period to the period of puberty according to a number of parameters: behaviour, appearance, weight gain, laboratory values. The diet of all animals was the same. Upon reaching four months of age, some of the animals were euthanized and histological examinations of the respiratory organs (tracheal mucosa and bronchi), spleen and testis structures were performed. The remaining animals were euthanized at the end of the recovery period - after 1 month. They also carried out histological studies of the above internal organs.

\section{Results and Discussion}

In the process of observing growing laboratory rats, it was noted that the animals of the first group, starting from the third month of life, were less active and gained better weight than the rats of the second group. This phenomenon became possible to explain only after receiving the results of histological studies: the testes of animals of the first group were atrophic. As is known, phenol is a very toxic compound and also causes impairment of the functions of the nervous system - apathy occurs, indifference to what is happening around, the body is in a depressed state [13]. Histological studies have found that changes in the type of stimulation in the organs of rats of the first group prevailed in the form of hyperplasia of the tracheal glands with areas of mucosal atrophy (Fig. 1), focal infiltration of the bronchial mucosa (Fig. 2), and hyperplasia of lymphoid structures of the spleen with an increase centers of growth of lymphoid follicles (Fig. 3), whereas pathological changes in the studied organs of animals of the second group were defined as insignificant hyperplasia of the tracheal glands (Fig. 4), hyperplasia of lymphoid follicles of the spleen (Fig. 5) and the absence of any changes in the structures of the bronchi during the entire observation period (Fig. 6). 


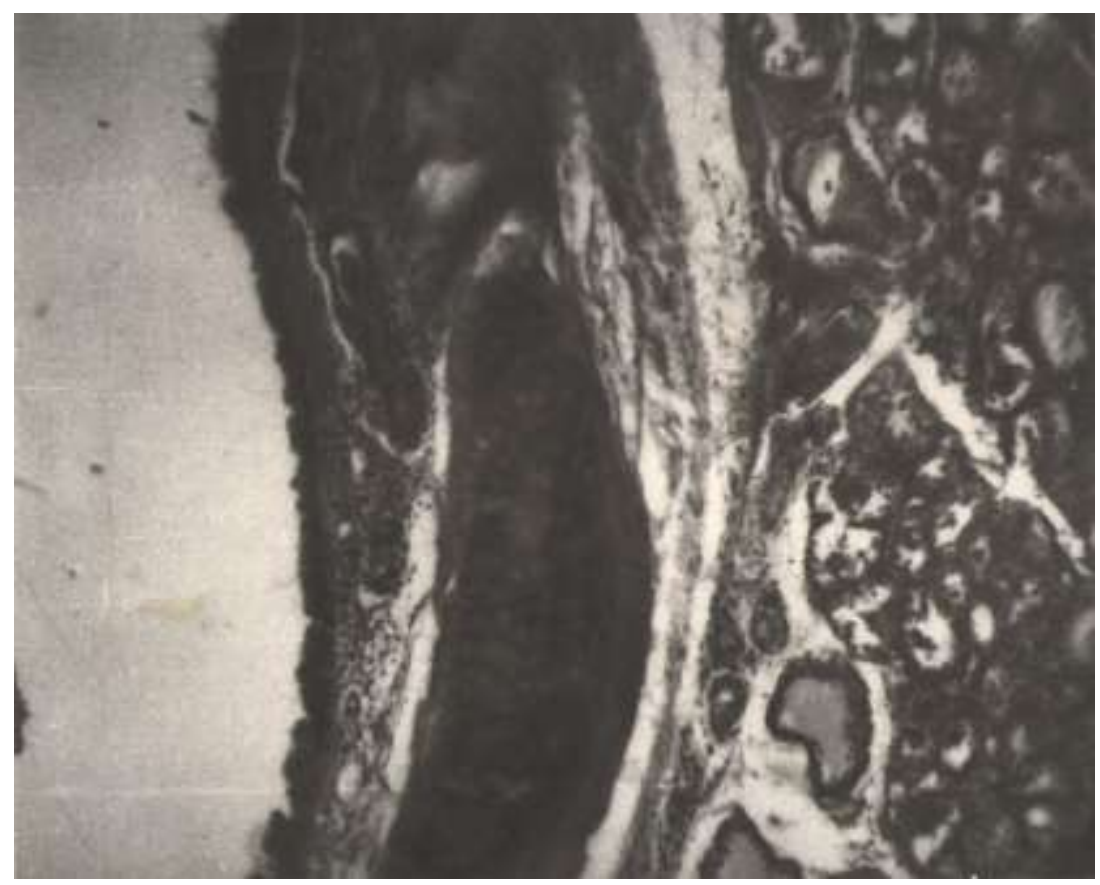

Figure 1: Hyperplasia Glands and Atrophy Mucous Membranes of Trachea



Figure 2: Focal Peribronchial Infiltration 




Figure 3: Hyperplasia Follicles of Spleen

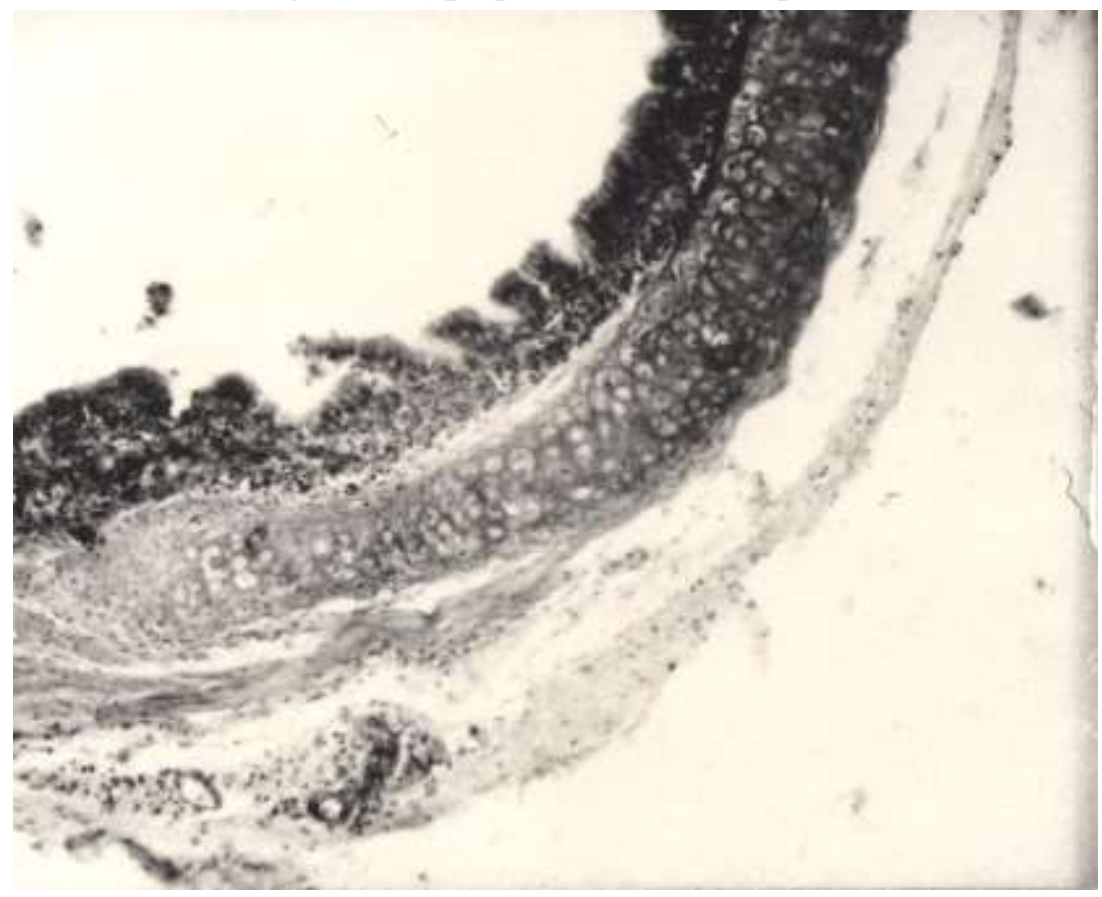

Figure 4: Medium Hyperplasia Glands of Trachea 


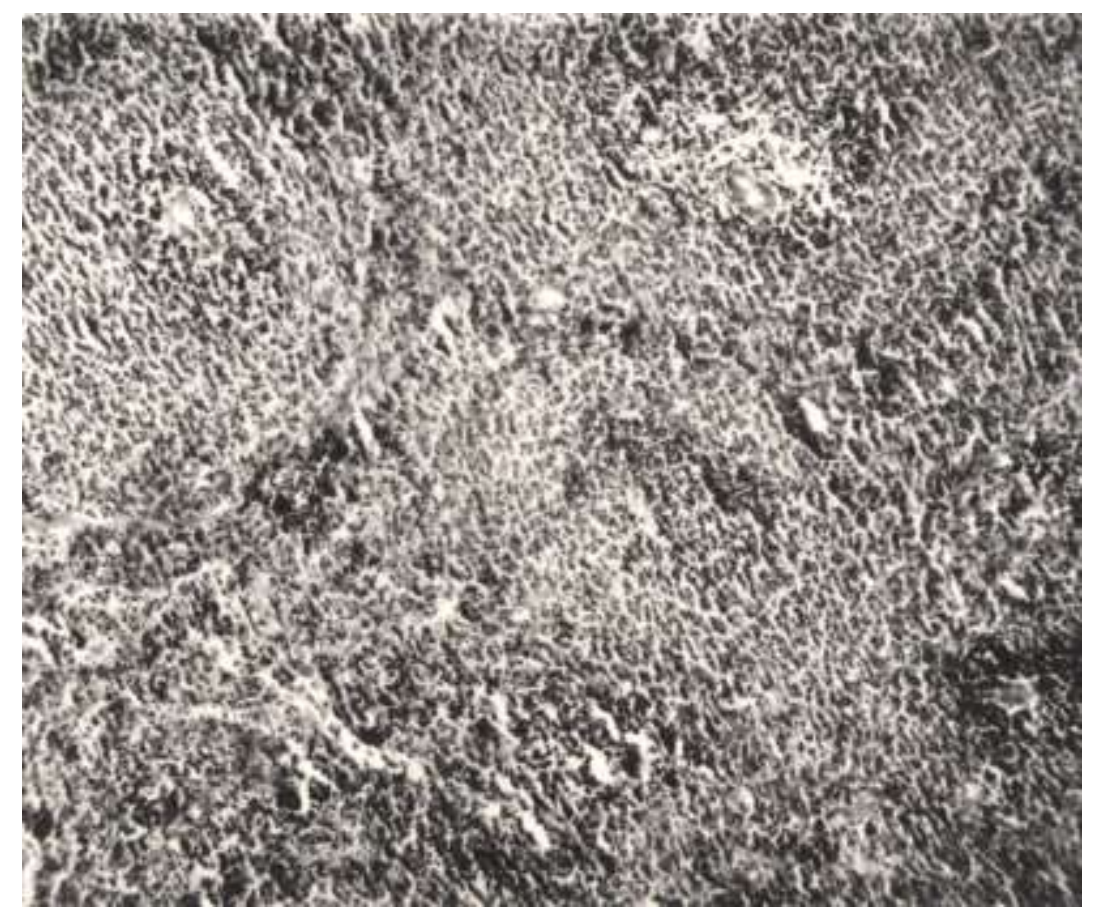

Figure 5: Hyperplasia Lymph Follicles of Spleen

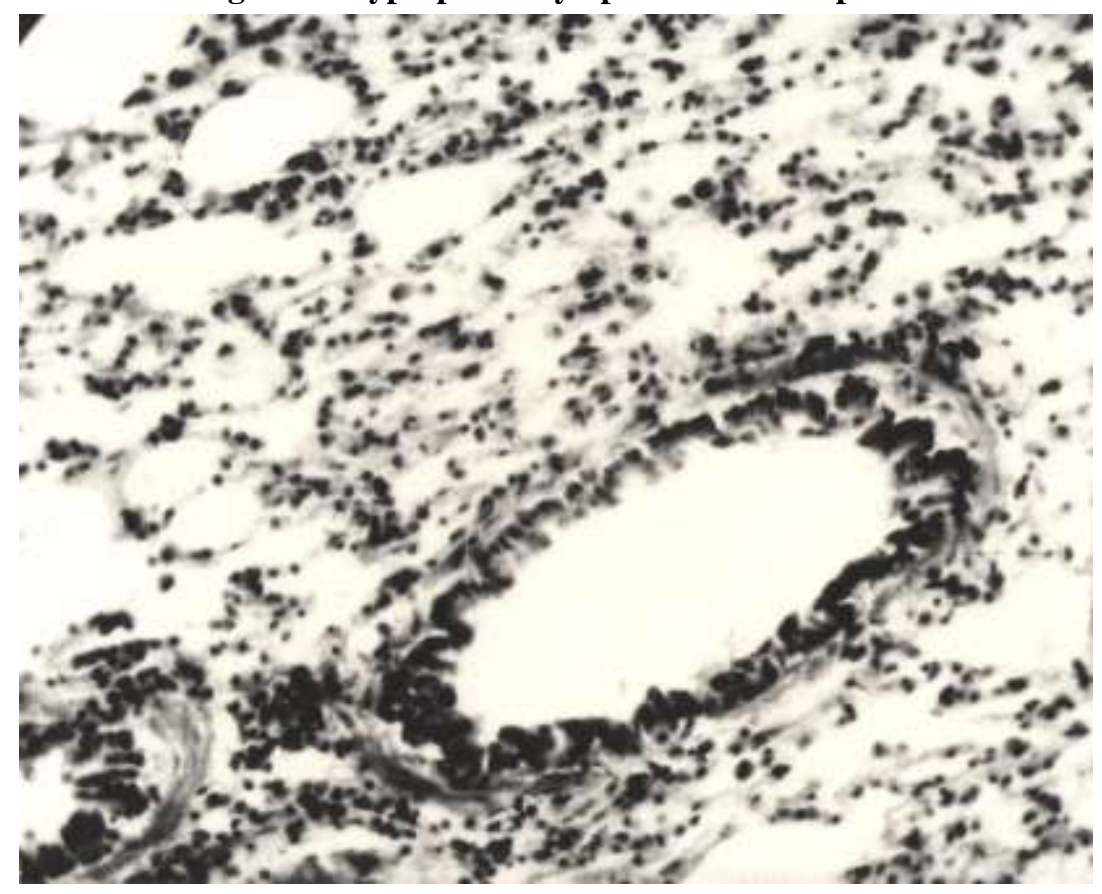

Figure 6: Physiological (Normal) Structure of Bronchus

The activity of the recovery processes of the affected structures was inversely related to the degree of air pollution. The animals of the first group after the recovery period remained structural disorders: cellular infiltration and sclerosis of the tracheal mucosa, focal cellular infiltration of the bronchi (Fig. 7) and atrophy processes of the lymphoid tissue of the spleen (Fig. 8). Thus, in a full-scale experiment, the adaptive abilities of animals are significantly reduced in individuals of the first group living in the immediate vicinity of an industrial enterprise, as confirmed by histological studies: the presence of marked irreversible changes in the organs of immunogenesis, in the mucous membranes of the trachea and bronchi. 


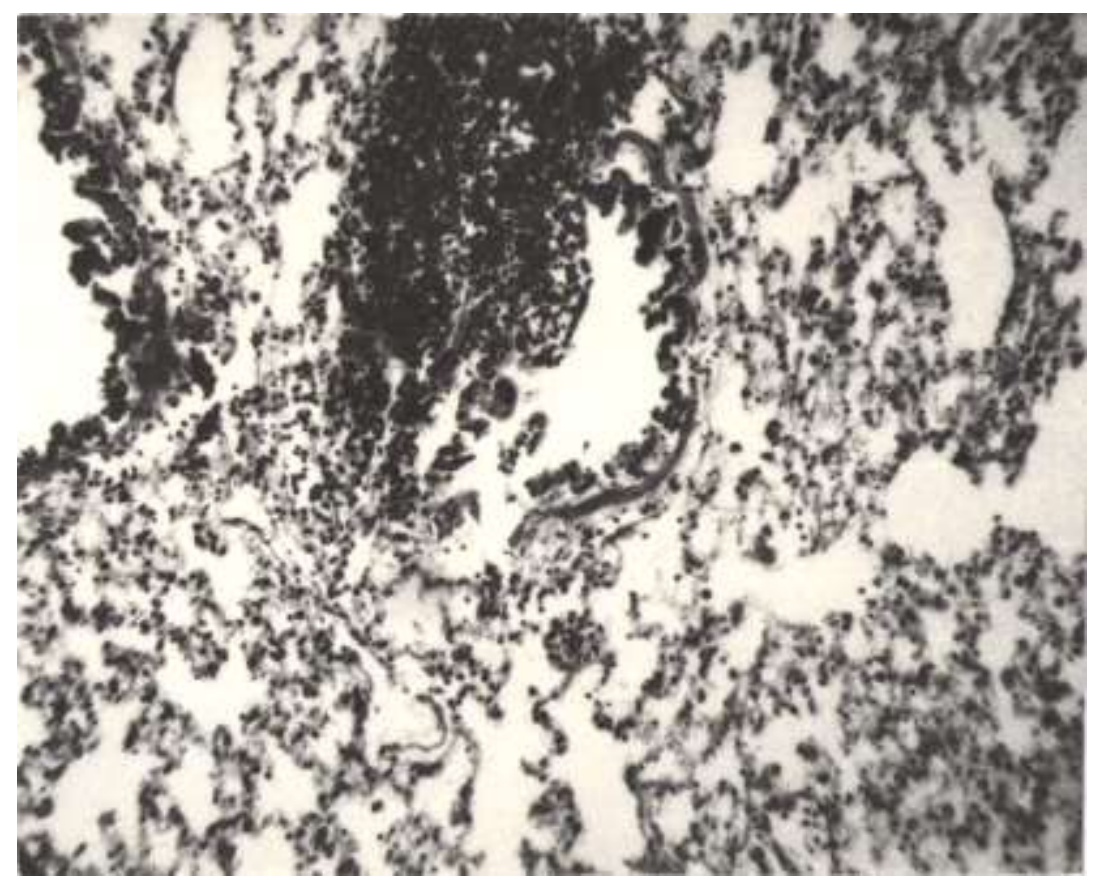

Figure 7: Cellular Infiltration



Figure 8: Atrophy Lymph Follicles of Spleen

The results of monitoring laboratory rats placed in chambers with specially created conditions showed that as the concentration of phenol increased above $0.1 \mathrm{mg} / \mathrm{m}^{3}$, deep irreversible destructive disorders developed in the form of tracheal atrophy and sclerosis (Fig. 9), complete atrophy lymphoid structures of the spleen (Fig. 10), increased secretion and edema of the epithelium of the bronchi of medium calibre (Fig. 11). At the same time, the regeneration phenomena were absent after the recovery period, whereas when exposed to low concentrations of phenol, the recovery process of the affected structures was quite active. 


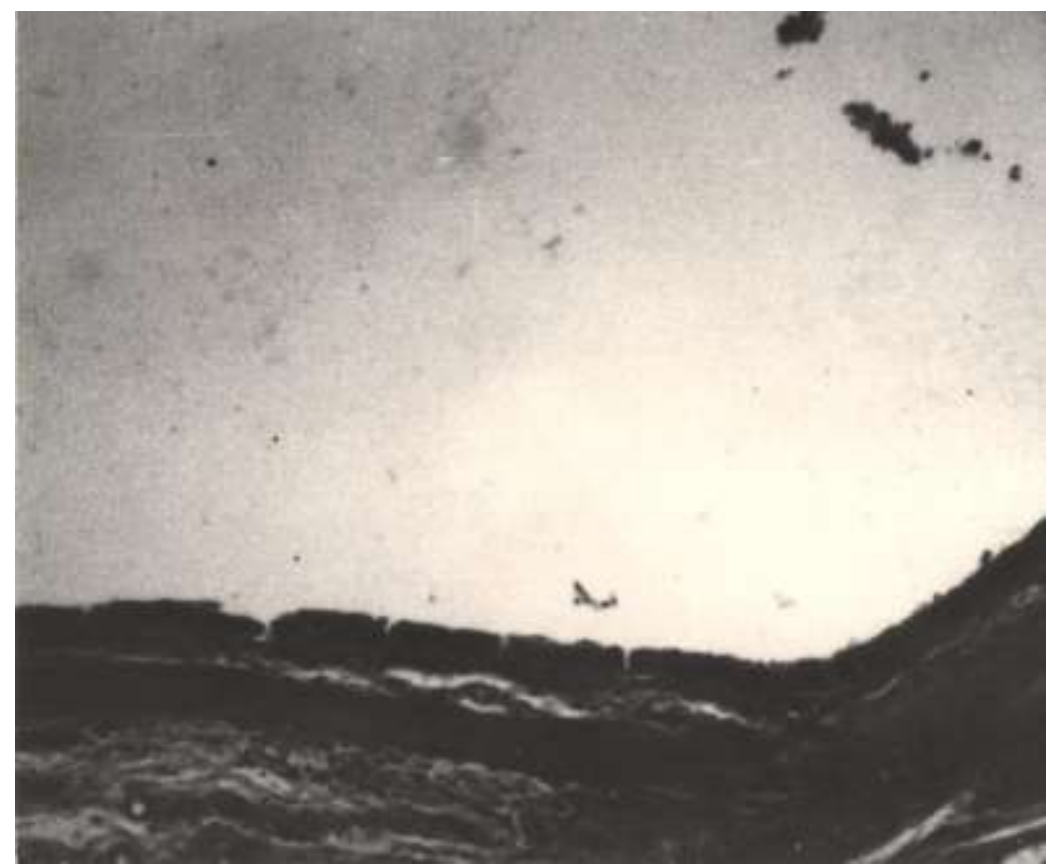

Figure 9: Atrophy and Sclerosis Mucous Membranes of Trachea

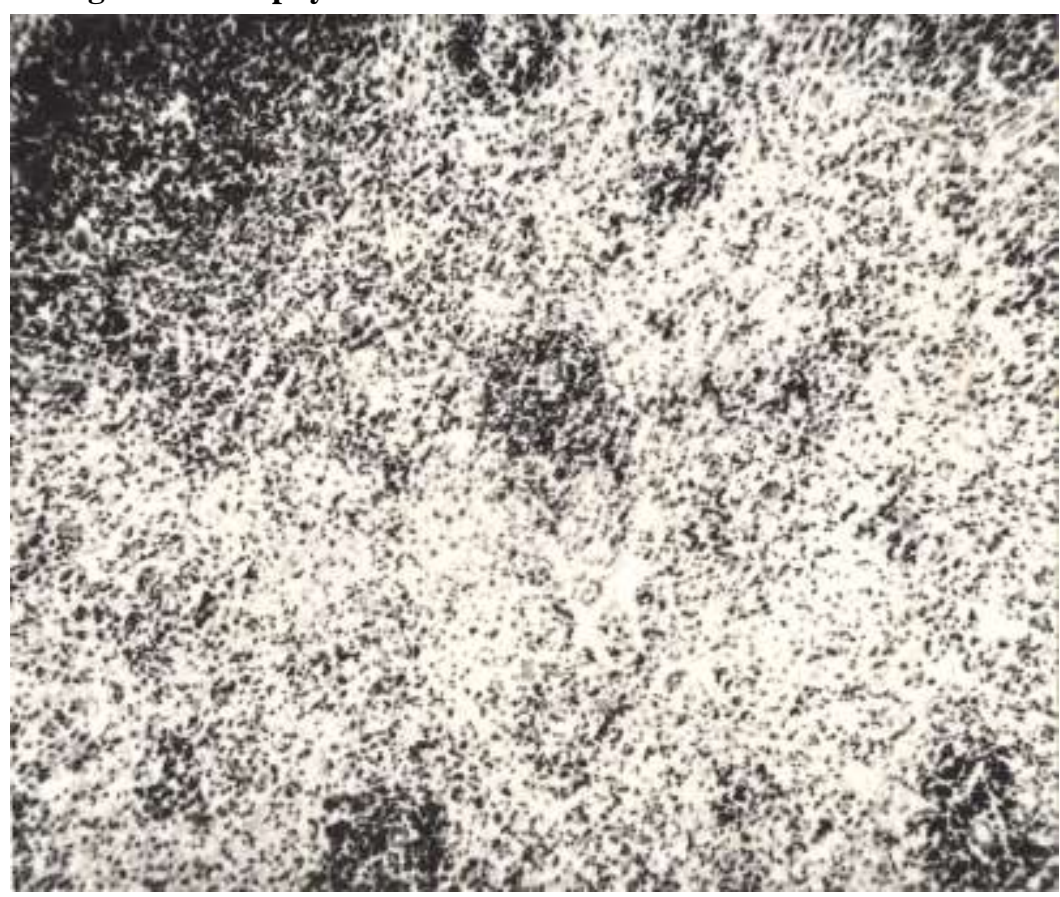

Figure 10: Total Atrophy Lymph Follicles of Spleen 


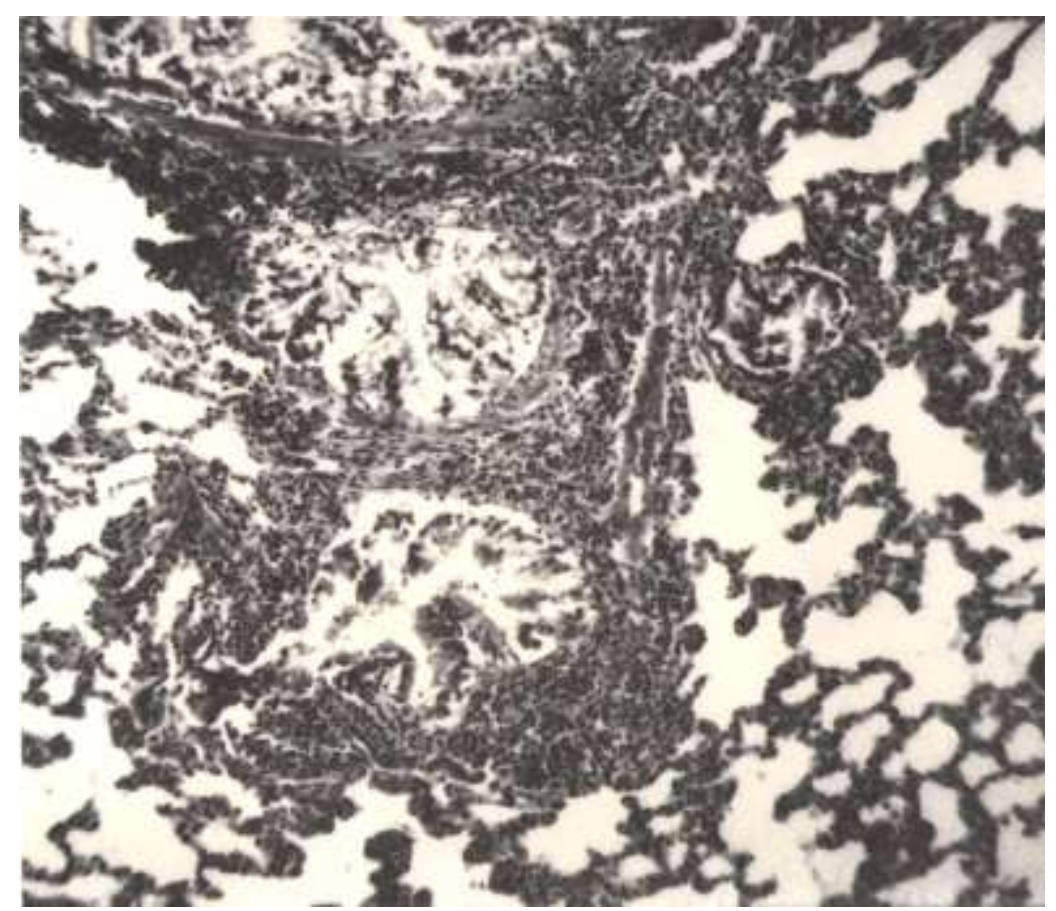

Figure 11: Hypersecretion and Edema of Interlobar Bronchus

\section{Summary}

Thus, harmful substances of atmospheric emissions of industrial enterprises, both comprehensively and individually, as in our experiment - phenol, can cause marked local irritating and general toxic effects on the body of white laboratory rats, leading to changes in the respiratory organs and immune system.

\section{Conclusion}

Obtained as a result of experimental studies, the data allowed to identify the causes of increased bronchovascular morbidity associated with morphological changes in the mucous membrane of the trachea, bronchi, spleen follicles. At the same time, irreversible destructive disorders in the respiratory organs and immunogenesis increased with the approach to the industrial complex, as well as with increasing concentration of phenol in the inhaled air.

\section{Acknowledgements}

The work is performed according to the Russian Government Program of Competitive Growth of Kazan Federal University.

\section{References}

[1] Smurov A.V., Snakin V.V., Komarova N.G. The current state of atmospheric air // Ecology of Russia, Educational edition, 2012, p. 12-33.

[2] SanPiN 2.2.1 / 2.1.1.1200-03 "Sanitary protective zones and sanitary classification of enterprises, structures and other objects" dated September 25, 2007 No. 74 (as amended by the Resolutions of the Chief State Sanitary Doctor of the Russian Federation of April 10, 2008 No. 25, dated 10/06/2009 No. 61, dated 09/09/2010 No. 122).

[3] Bratsuk A. A., Esimova A. T., Ignatovich I. A. Analysis of the statistics of harmful emissions into the air // Young Scientist. - 2017. - No.50. - p. 129-130.

[4] Bennet B.G. Selection of an Exposure commitment to Environmental Seal. Sci of Total Environ. - 1983. No.2. -P.117-127.

[5] Zabolotskaya N.N. Prediction of outcomes and prevention of complications of acute respiratory infections in young children living in the mining and metallurgical industrial center Dissertation of the candidate of medical sciences, 1987. - $166 \mathrm{p}$.

[6] Atmospheric emissions and air pollution in the city [Web source] - Access mode: http://ekrost.ru/poster/vliyanie-atmosfernyh-vybrosov-na-ekologicheskuyu-situaciyu-goroda.html.

[7] What is the danger of phenol in the air and what are the norms [Web source] - Access mode: https://nmedicine.net/v-chem-opasnost-fenola-vozduxe-normy.

[8] Lipatov G.Ya., Adrianovsky V.I., Sharipova N.P., Borisenko L.A. Emissions of harmful substances from metallurgical buildings of nickel plants // Basic research. - 2014. - № 10-4. - with. 689-692. 
[9] Organic Pollutants of the Environment [Web source] - Access Mode: http://www.activestudy.info/organicheskie-zagryazniteli-okruzhayushhej-sredy/

[10] Kagawa J. Health Effects of air pollutants and their management // Atmospheric Enviroment. - 1984. - No.3. v.18. - p.613-620.

[11] Saric M., Gomzi M., Hrustic O. Comparison of industrial workers // Scand. J.Work Environ Health.-1982.No.8.-p.6.

[12] Properties of phenol and its effect on the human body [Web source] - Access mode: https://prootravlenie.ru/ximiya/fenol-svojstva-vliyanie-na-organizm-cheloveka.

[13] Toxicological Profile for Phenol // U.S. Department of Health and Human Services. - 2008. - p. 269 https://www.atsdr.cdc.gov/ToxProfiles/tp115.pdf

[14] Pierrehumbert G, Pierre-Oliver D, Tardif R, et al. 2002. Phenol, lead, and mercury: II. Compartmental based toxicokinetic modeling. Toxicol Lett 134: 165-175

[15] Wallace J. 1996. Phenol. In: Kroschwitz JI, Howe-Grant M, eds. Kirk-Othmer encyclopedia of chemical toxicology. 4th ed. New York, NY: John Wiley \& Sons, 592-602 